\title{
Risk Analysis is a Prerequisite for Quality Management of Traction Rolling Stock Repairs
}

\author{
Vladimir Gaponov ${ }^{1}$, Dmitriy Kuznetsov ${ }^{1,2}$, Andrey Khvostikov ${ }^{1,3,}$, and Roman Alekhin ${ }^{4}$ \\ ${ }^{1}$ Don State Technical University, Rostov-on-Don, Russia \\ ${ }^{2}$ South-Russian State Polytechnic University, Novocherkassk, Russia \\ ${ }^{3}$ Rostov State Transport University, Rostov-on-Don, Russia \\ ${ }^{4}$ KZ Rostselmash LLC, Rostov-on-Don, Russia
}

\begin{abstract}
The paper considers a new version of IRIS ISO/TS 22163:2017 standard in relation to the quality of repair of complex equipment in the railway industry. It is shown that the new version of ISO/ TS 22163:2017 standard provides for the need of organizations to conduct risk analysis and accounting in their work. The authors propose to consider as an example a well-established analysis of the types and consequences of potential defects in FMEA process. The use of FMEA analysis made it possible to consider the significance of various risks of the quality of traction rolling stock repair, as well as to establish the importance of quality control operations for impregnation of a traction motor.
\end{abstract}

\section{Introduction}

In modern conditions, the issue related to quality management of the repair of complex equipment in the railway industry and, above all, traction rolling stock, is quite relevant. Despite the fact that in the structure of the railway engineering industry, locomotives occupy only $17 \%$ of the total cost, the importance of the quality condition of traction rolling stock is great. As this equipment wears out, it becomes clear that in order to continue its operation, it is necessary to learn not only to qualitatively repair this equipment, but also to develop new approaches to repair, since the spare parts park has sharply decreased with a simultaneous increase in the number of parts requiring replacement [1].

It is possible to create a new approach to the repair of rolling stock and improve its quality by integrating a modern quality management system (QMS) at the enterprise, which will make it possible to manage the quality of repairs in real time. Currently, the International Railway Industry Standard (IRIS) is a suitable international standard for building QMS in the railway industry. IRIS was formed by the European Association of the Railway Industry (UNIFE) to evaluate enterprise management systems. When creating it, UNIFE took into account the problems and peculiarities of the railway industry. IRIS has been designed to be fully compatible with the ISO 9000 series. This document enables one to create a business management system (BMS), which carries out continuous improvement of quality management. A special place in this standard is given to measures to prevent and reduce the

\footnotetext{
* Corresponding author: xvost72@mail.ru
} 
number of defects in the supply chain of railway equipment [2]. Emergence of a new version of ISO 9000-2015 series of standards revealed the current trend of improving the functioning of the existing QMS, namely, the need to take into account and assess the risks of creating new equipment and new technologies. Indeed, because of the rapidly changing external environment, the found technical solutions may not have time to adapt to the new requirements and demands of consumers. The development of a quality management system based on the 'just-in-time' principle (JIT technology) has further exacerbated the issue not only of product quality, but also of its delivery to the consumer. The need to take into account risks has led to a significant modification of ISO 9000 standards, which, in turn, are fundamental to IRIS standard for the railway industry.

All of the above fully applies to the organization and technologies of traction rolling stock repair. Problems of low-quality raw materials, non-fulfillment of technology elements, lack of modern and reliable methods of flaw detection lead to irregular failure of traction rolling stock. All of the above problems create risks that reduce reliability and quality of repairs. The new version of IRIS ISO/TS 22163:2017 standard is largely aimed not only at meeting consumer expectations and continuous improvement, but also at the need to take risks into account when creating and repairing traction rolling stock. Table 1 below provides references in IRIS ISO/TS 22163:2017 standard that require organizations to conduct risk analysis and accounting in their work.

Table 1. Quotes about the need for risk management in IRIS standard

\begin{tabular}{|l|l|}
\hline $\begin{array}{c}\text { Clauses of the } \\
\text { standard }\end{array}$ & \multicolumn{1}{c|}{ Text } \\
\hline $5.1 .2 \mathrm{~b}$ & $\begin{array}{l}\text { 'Top management must demonstrate leadership in customer orientation } \\
\text { by ensuring that ... the risks and opportunities that can affect conformity } \\
\text { of products and services and ability to improve customer satisfaction are } \\
\text { identified and addressed.' }\end{array}$ \\
\hline 6.1.(6.1.1-6.1.4) & 'Actions to address risks and opportunities'. \\
\hline 8.1 .1$. & $\begin{array}{l}\text { 'The organization must establish, implement and maintain a documented } \\
\text { process for planning the transfer of processes to be performed by third } \\
\text { parties that can affect the quality of the organization's products or services. } \\
\text { This process must include ... } \\
\text { b) risk assessment; }\end{array}$ \\
\hline 8.1 .3 .6$. & $\begin{array}{l}\text { 'Project Human Resource Management. } \\
\text { The organization must establish the required competencies and } \\
\text { appropriate levels for project managers and key project team members in } \\
\text { relation to.... } \\
\text { j) risk and opportunity management; }\end{array}$ \\
\hline 8.1 .3 .8$. & 'Project Risk and Opportunity Management' \\
\hline
\end{tabular}

For the purpose of further qualitative and quantitative analysis of risks that reduce reliability and quality of repair of traction rolling stock, the authors propose to consider an example of integration into QMS of a well-proven analysis of the types and consequences of potential defects in FMEA process. The experience of using FMEA method has shown that with its help, in general, it is possible to identify precisely those factors that cause the greatest risk to the consumer. Moreover, two subclauses of IRIS ISO/TS 22163:2017 standard explicitly refer to FMEA method as a recommended risk analysis method:

- 6.1.3 '... FMEA analysis can be applied to risk management in business planning, design and development, projects and production';

- 8.1.5. k) '... Accompanying documented information, such as an FMEA analysis report' [2]. 
It is known that FMEA analysis is divided into two types - DFMEA structural analysis and PFMEA process analysis. Further, as an example of practical use of FMEA method, the authors consider the analysis of PFMEA (Process Failure Modes and Effect Analysis PFMEA, hereinafter PFMEA) processes for the repair of traction rolling stock.

Typically PFMEA is a technology for analyzing the possibility of potential product defects at the end user, directly related to the production process. PFMEA can be carried out for both developed new products and serial products. The main goal of PFMEA is to identify and assess the risks of potential product defects, to propose corrective measures, thereby reducing possible consumer dissatisfaction. PFMEA does not cover the analysis of statistical and economic indicators, including the costs of corrective measures related to the prevention of potential defects that arise, however, the PFMEA methodology can, and in most cases, is applied in combination with other methods of analysis. For example, Pareto chart, Ishikawa chart, histograms, etc. [3, 4].

The PFMEA method is described in some detail in the literature. The purpose of this work is to describe practical application of this method for specific conditions for the repair of traction rolling stock at a railway enterprise. The application of PFMEA in the conditions of traction rolling stock repair will be carried out as follows.

\section{Initialization, raw data, and defining analysis boundaries}

The PFMEA initialization process consists of making a decision by the stakeholder - the initiator to conduct this analysis. Such a decision can be made at a technology council or a meeting, in turn, initiated by some event. For example, formation of a quality plan for next year, for a specific product, in this case, traction rolling stock.

In the course of formation of the quality plan, in this case, statistical data were used presented in the form of a Pareto chart for reasons of failures of the repaired traction railway equipment at the end user for a certain period of time. For most enterprises, the use of Pareto analysis means choosing the direction of efforts of the management of the entire team, which will allow for continuous improvement in the future. The use of a Pareto chart enables one to order certain types of defects by significance or importance. In this case, it has been established that one of the most common complaints is the 'turn-to-turn short circuit of the winding' of the traction electric motor (TEM) $[4,5]$.

Next, it is necessary to determine the boundaries of the analysis, that is, to select the processes that affect the quality of the TEM anchor. The boundaries are determined in the course of the technological council, the agenda of which is the analysis of the complaint 'turn-to-turn short circuit of the winding'. As a result of the council, it was decided to carry out PFMEA of the engine impregnation process included in the 'Road map', thus the boundaries of PFMEA were determined [4, 6].

The initial data for analysis must contain information on technological processes and products, requirements for the product as a whole and its individual components, environmental factors. Materials and data for analysis may include drawings, road maps, work instructions, regulations and other technological documents. The study of technological processes should include not only the study of documentation, but also a face-to-face analysis of the situation of technological processes at workplaces.

\section{PFMEA team formation and brainstorming}

The leader (initiator), and in our case the head of workshop No. 1, forms a PFMEA-team based on the decision of the technology council. Usually, in real production conditions, as in this case, the PFMEA-team should consist of specialists, who, in turn, are competent 
employees of the enterprise. The number of people entering the team is unlimited. During the analysis, the composition of the team can be changed, if it is justified and necessary. The work of the team begins with filling in the header of the PFMEA protocol (Figure 1), when all the required fields are filled in, the analysis proceeds to the next stage [4].

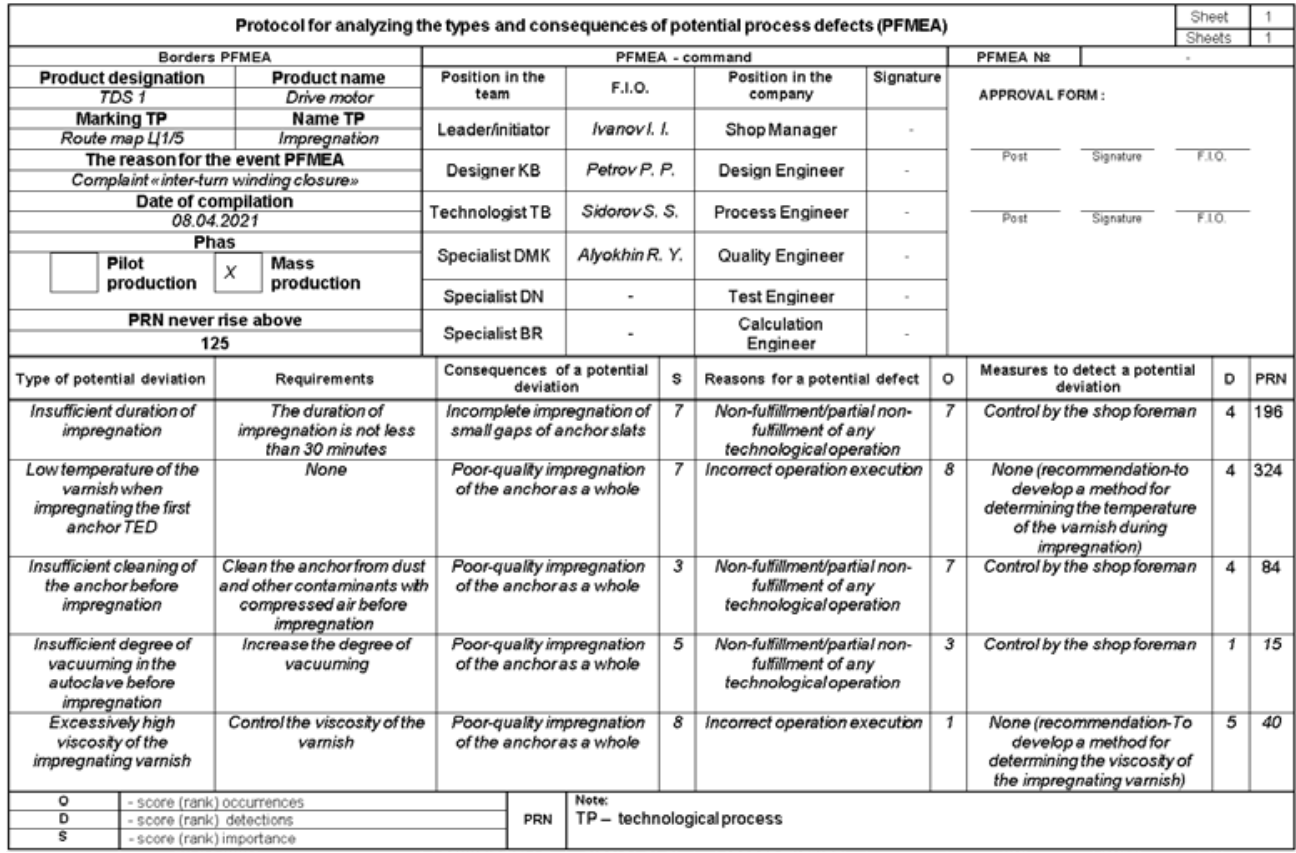

Fig. 1. PFMEA analysis table

The next stage of PFMEA is brainstorming, during which the operations associated with the selected process are considered. It is assumed that if all operations are performed correctly, the product will be free from obvious, latent or potential defects.

While reviewing operations, the PFMEA team makes all kinds of assumptions. Potential defects should only be described in technical language. When formulating a defect, it is necessary to take into account that previous operations meet the requirements and are not the cause of a defect in the operation in question. Even seemingly insignificant or unlikely potential defects must not be overlooked at this stage. A final list of potential process defects is then compiled by screening.

Thus, the PFMEA team has determined that the most likely potential defects in the impregnation process are:

- insufficient duration of impregnation;

- low temperature of varnish during impregnation of the first anchor of TEM;

- insufficient cleaning of TEM anchor before impregnation;

- insufficient degree of evacuation in the autoclave before impregnation;

- excessively high viscosity of the impregnating varnish, etc.

\section{Determining the causes of potential defects}

With the help of brainstorming, the PFMEA team examines each potential defect and determines the cause of its manifestation. At this stage, one should also pay attention to even minor conditions for the occurrence of a potential defect. After that, by screening, a list of the most probable causes is formed. In this case, these are: 
- non-fulfillment of any technological operation or partial non-fulfillment of an operation;

- incorrect operation (for example, inappropriate process parameters - speed, pressure, etc.);

- performing unforeseen (harmful) actions;

- constructive flaw in the working equipment.

As an example of a partial failure to perform an operation, one can mention cases where the impregnation duration is reduced in comparison to the requirements of the technological process. The technological road chart indicates the requirement for the impregnation duration - 30 minutes. However, the impregnator often evaluates the process visually - by reducing the amount of displaced air. And if, after 10 minutes, the release of displaced air bubbles is not detected, the impregnation stops $[7,8,9]$.

As an example of incorrect performance of an operation (inappropriate process parameters), inappropriate parameters of the impregnation process of the first TEM anchor during a work shift should be indicated. Since the varnish is supplied for impregnation without preheating (by pumping it from the storage tank into the autoclave), the temperature of the injected varnish is thus determined by the ambient conditions (air temperature in the workshop). Since the ambient temperature range is small (from 15 to $35^{\circ} \mathrm{C}$ ), it can be confidently asserted that the temperature of the varnish supplied for the impregnation of the first anchor is also within the indicated limits. Considering the fact that the temperature of the anchor supplied for impregnation is $140-146^{\circ} \mathrm{C}$, it becomes clear that in the process of impregnation due to high temperature of the anchor, the varnish heats up to $70-75^{\circ} \mathrm{C}$. After the end of impregnation, the varnish is downloaded and the TEM anchor is removed from the impregnation tank. Then the varnish is again fed into the autoclave, the measurements show that the second anchor is placed in the already heated varnish with a temperature exceeding $45^{\circ} \mathrm{C}$. The second anchor heats this varnish to $86^{\circ} \mathrm{C}$, etc.

An example of a constructive flaw may be the lack of possibility of heating the varnish before the start of impregnation.

\section{Assessment of significance, occurrence and detection of possible causes, calculation of RPN}

For each detected defect, team members assess its significance by a point (rank) S. The point depends on the severity of the defect's consequences and is determined expertly using a 10point scale. The assessment is based on the assumption that significance applies only to the consequence. For the impregnation process under consideration, such a defect as 'insufficient cleaning of the anchor before impregnation' is most likely of the least significance, since it is easily eliminated (point 3). Point 10 (catastrophic impact in which a manufacturer or supplier could face criminal penalties) is given in exceptional cases. In this case, the maximum number of points is 'excessively high viscosity of the impregnating varnish' (point 8 ), since the impregnation of the anchor with an initially poor-quality varnish is extremely difficult.

Using the appropriate typical scale, the PFMEA-team expertly determines the points (ranks) of the occurrence of O. A 10-point scale is also most often used (in the case of a low probability, the point is 1 , with the regular occurrence of ROE failure it is 10). For the considered impregnation process 'low varnish temperature during impregnation of the first anchor', the estimate of the probability with which this type of defect is expected to appear is taken equal to 8 .

In addition, a D-criterion (Detection) is developed for each cause of potential nonconformity. The most commonly used is 10-point scale. For hidden defects, one can accept a score equal to 10. A parameter equal to one means that such a defect is detected with 
$100 \%$ accuracy. In this case, all defects with a greater or lesser degree of probability can be detected on site, therefore, points are accepted, in the range from 1 to 5, and they are entered into the analysis protocol.

Scales for determining the points (ranks) S, O and D are formed before the start of the analysis, during the integration of PFMEA into the QMS enterprise. Typically, each business sets its own criteria for assessing potential defects. Therefore, it is wise to use only local reference material when conducting PFMEA in an enterprise.

After identifying all the parameters, by multiplying them, the risk priority number (RPN) is determined - a generalized quantitative characteristic of the object of analysis. The objects of analysis are sorted in descending order of the RPN values. The higher the RPN, the more significant the violation and its consequences. First of all, it is necessary to eliminate or reduce the risk of defects and malfunctions in which this value exceeds 125 . Violations with an average level of threat gain from 40 to 100 points, and an RPN of less than 40 indicates that a failure is insignificant, occurs rarely and can be found without any problems [4].

Analyzing the data obtained, it can be seen that the maximum RPN parameter has a defect with the description 'Low varnish temperature during impregnation of the first TEM anchor', equal to 324. Such a high significance of the risk predetermines the need for administration efforts to eliminate this problem in the first place. In addition, almost all of the above risks could be eliminated if the company developed and used the technology of final quality control, i.e. control of the degree of impregnation of engines. This operation would prevent polymerization of insufficiently impregnated engines. Because after the motors are polymerized in a baking oven, the situation becomes irreversible.

\section{Conclusions}

A new version of IRIS ISO/TS 22163:2017 standard was considered in relation to the quality of repair of complex equipment in the railway industry.

It is shown that the new version of IRIS standard provides for the need for organizations in their work to analyze and account for risks.

The PFMEA method was proposed for the analysis and accounting of risks.

Using the PFMEA method, the significance of various risks at the stage of impregnation of a traction motor of a rolling stock was analyzed, and also made it possible to establish the importance of quality control operations of impregnation of a traction motor.

\section{References}

1. D.M. Kuznetsov, A.G. Khvostikov, V.L. Gaponov IRIS stsndart implementation for improvement quality management in repair of traction rolling stock, Vestnik RGUPS, v. 2 (78), pp 54-61, (2020).

2. Railway applications - Quality management system - Business management system requirements for rail organizations: ISO 9001:2015 and particular requirements for application in the rail sector, p. 72 (2017).

3. A. Cherpakov, I. Egorochkina, E. Shlyakhova, A. Kharitonov, A. Zarovny, S. Dobrohodskaya, Using technique vibration diagnostics for assessing the quality of power transmission line supports repairs, MATEC Web of Conferences, v. 106, 04009, (2017).

4. V.E. Godlevsky, A.Ya. Dmitriev, G.L. Yunak, V.Ya. Kokotov, Application of the method for analysis of types, causes and consequences of potential nonconformities (FMEA) at various stages of life cycle of automotive products, (Perspective, Samara, 2002). 
5. I.Y. Zilberova, V.D. Mailyan, I.V. Novoselova, Modern methods for evaluating the technical and organizational-technological solutions for repair and construction production, IOP Conference Series: Materials Science and Engineering, v. 698, 055013, (2019).

6. T. Finochenko, I. Yizkov, L. Dergacheva, Risk Management in Transportation Safety System, IOP Conference Series: Earth and Environmental Science, v. 2, pp. 144-145, (2021).

7. D. Molochnikov, R. Khalimov, I. Gayaziev, D. Rudoy, A. Olshevskaya, The improvement of the technique for determining technical condition of repair and maintenance equipment, 8th Innovative Technologies in Science and Education, ITSE 2020, v. 210, 08006, (2020).

8. M.S. Stepanov, Y.M. Dombrovskii, V.N. Pustovoit, Micro-Arc Diffusion Impregnation of Steel with Carbon and Carbide-Forming Elements, Metal Science and Heat Treatment, v. 56, pp. 308-312, (2017).

9. T. Ripol-Saragosi, L. Ripol-Saragosi, I. Smychok, Compressed air quality increase for rolling stock pneumatic systems based on energy efficiency, Transport Problems, v. 13, pp. 13-21, (2021). 